Check for updates

Cite this: RSC Adv., 2019, 9, 4834

Received 11th January 2019

Accepted 2nd February 2019

DOI: $10.1039 / c 9 r a 00264 b$

rsc.li/rsc-advances

\section{Preparation, crystal structure and luminescence properties of a novel single-phase red emitting phosphor $\mathrm{CaSr}_{2}\left(\mathrm{PO}_{4}\right)_{2}: \mathrm{Sm}^{3+}, \mathrm{Li}^{+} \dagger$}

\author{
Yuying Chen, ${ }^{\text {ab }}$ Qingfeng Guo, (D) *ab Libing Liao, (D)*c Mingyue He, ${ }^{\text {ab }}$ Tianshuai Zhou, ${ }^{c}$ \\ Lefu Mei, ${ }^{\star c}$ Marcin Runowski (iD d and Bin Ma ${ }^{e}$
}

Single-phase $\mathrm{CaSr}_{2}\left(\mathrm{PO}_{4}\right)_{2}: \mathrm{Sm}^{3+}, \mathrm{Li}^{+}$phosphors were prepared via a high-temperature solid-state method under air. The powder X-ray diffraction patterns, scanning electron microscopy images, photoluminescence spectra, and concentration-dependent emission spectra were measured to characterize the as-prepared phosphors and luminescence decay curves. The results showed that the $\mathrm{CaSr}_{2}\left(\mathrm{PO}_{4}\right)_{2}: \mathrm{Sm}^{3+}, \mathrm{Li}^{+}$phosphors exhibited red luminescence, and the emission spectra of the phosphors consisted of four sharp peaks at around 565, 601 (the strongest one), 647 and $707 \mathrm{~nm}$. The optimum doping concentration of $\mathrm{Sm}^{3+}$ ions was 0.09 (mol concentration), and the mechanism of energy transfer among $\mathrm{Sm}^{3+}$ ions was defined to be quadrupole-quadrupole $(q-q)$ interactions using Dexter's theory. The Blasse concentration quenching method was used to determine the critical distance $R_{\mathrm{c}}$ for energy transfer among $\mathrm{Sm}^{3+}$ as $10.99 \AA$. The results indicate that the as-prepared phosphors have good thermal stability with an activation energy of $0.773 \mathrm{eV}$ via temperature-dependent emission spectra. Therefore, $\mathrm{CaSr}_{2-2 x}\left(\mathrm{PO}_{4}\right)_{2}: x \mathrm{Sm}^{3+}, x \mathrm{Li}^{+}$materials can be used as red-emitting phosphors for UV-pumped white-light emitting diodes.

\section{Introduction}

High efficiency, long-life and non-polluting light sources are urgently needed., ${ }^{\mathbf{1} 2}$ In contrast to traditional lighting sources, white light emitting diodes (w-LEDs) offer high energy conversion efficiency, small volume, low starting voltage, long durability and good color rendering..$^{3-5}$ Phosphors are an important component of LEDs, but have a poor color rendering index when used in w-LEDs. Multi-phosphor mixing usually results in color imbalance and instability at higher temperatures, effectively limiting their applications. Therefore, new high efficiency phosphor systems are needed to improve the luminous

${ }^{a}$ School of Gemology, China University of Geosciences, Beijing 100083, China. E-mail: qfguo@cugb.edu.cn

${ }^{b} J e w e l r y$ and Mineral Materials Laboratory of Experimental Teaching Demonstration Center, Beijing, China

${ }^{\circ}$ Beijing Key Laboratory of Materials Utilization of Nonmetallic Minerals and Solid Wastes, National Laboratory of Mineral Materials. School of Materials Sciences and Technology, China University of Geosciences, Beijing 100083, China. E-mail: clayl@ cugb.edu.cn;mlf@cugb.edu.cn

${ }^{d}$ Adam Mickiewicz University, Faculty of Chemistry, Department of Rare Earths, Umultowska 89b, 61-614 Poznań, Poland

${ }^{e}$ Qinghai Provincial Key Laboratory of New Light Alloys, Qinghai Provincial Engineering Research Center of High Performance Light Metal Alloys and Forming, Qinghai University, Xining 810016, PR China

$\dagger$ Electronic supplementary information (ESI) available. See DOI: $10.1039 / \mathrm{c} 9 \mathrm{ra00264b}$ efficiency of LEDs-especially those excited by near ultraviolet or blue chips. Lanthanides have transitions between $5 \mathrm{~d} \rightarrow 4 \mathrm{f}$ and $4 \mathrm{f} \rightarrow 4 \mathrm{f}$, leading to tunable multicolor luminescence in the UV-Vis-NIR range, long radiative lifetimes, and narrow absorption and emission bands; thus, lanthanides are very important in the display and lighting fields. ${ }^{6-8}$ Red or orange-red emitting phosphors can be prepared via appropriate doping of the selected materials with lanthanide ions, i.e. $\mathrm{Eu}^{3+}$ or $\mathrm{Sm}^{3+}$. Compared with $\mathrm{Eu}^{3+}$-doped materials, $\mathrm{Sm}^{3+}$-doped phosphors can be easily excited in the blue region, which is useful for excitation in the near-ultraviolet (n-UV) InGaN-based LED chip (350-420 nm). ${ }^{9}$ Moreover, the use of $\mathrm{Sm}^{3+}$ ions is much more cost-effective than very expensive $\mathrm{Eu}^{3+}$ ions.

Whitlockite has a chemical formula $\mathrm{M}_{3}\left(\mathrm{PO}_{4}\right)_{2}(\mathrm{M}=\mathrm{Ca}, \mathrm{Sr}$, $\mathrm{Ba}$ ) and has been investigated as a potential host for luminescent materials. ${ }^{\mathbf{1 0 - 1 2}} \mathrm{CaSr}_{2}\left(\mathrm{PO}_{4}\right)_{2}$ belongs to whitlockite, and it can be a suitable host, for phosphors due to its excellent luminescence properties. ${ }^{13}$ However, research into the luminescence properties and structure characteristics of $\mathrm{Sm}^{3+}$ doped $\mathrm{CaSr}_{2}\left(\mathrm{PO}_{4}\right)_{2}$ is rare. Here, a novel $\mathrm{Sm}^{3+}$ doped $\mathrm{CaSr}_{2}\left(\mathrm{PO}_{4}\right)_{2}$ phosphor was prepared for the first time, and its luminescence and crystal structures were investigated in detail.

Here, a series of the $\mathrm{CaSr}_{2-2 x}\left(\mathrm{PO}_{4}\right)_{2}: x \mathrm{Sm}^{3+}, x \mathrm{Li}^{+}$phosphors were synthesized by a high-temperature solid-state reaction method in air atmosphere, for the first time. The samples were characterized by X-ray diffraction (XRD), scanning electron microscopy (SEM), photoluminescence excitation (PLE) and 
emission (PL) spectra, and decay curves. The XRD pattern of the $\mathrm{CaSr}_{2}\left(\mathrm{PO}_{4}\right)_{2}$ phase is similar to whitlockite mineral, which crystallizes in the space group $R 3 c$. In addition, the as-prepared phosphors have good thermal stability via temperaturedependent emission spectra. The results indicate, that the asprepared $\mathrm{CaSr}_{2}\left(\mathrm{PO}_{4}\right)_{2}: \mathrm{Sm}^{3+}, \mathrm{Li}^{+}$phosphor can act as a UV convertible, red phosphor for w-LEDs.

\section{Experimental section}

\subsection{Materials and synthesis}

The $\mathrm{CaSr}_{2-2 x}\left(\mathrm{PO}_{4}\right)_{2}: x \mathrm{Sm}^{3+}, x \mathrm{Li}^{+}(x=0-0.3)$ powder samples were synthesized via high temperature solid-state method. The starting materials, $\mathrm{CaCO}_{3}$ (99.9\%), $\mathrm{SrCO}_{3}(99.9 \%), \mathrm{Li}_{2} \mathrm{CO}_{3}$ (99.9\%), $\left(\mathrm{NH}_{4}\right)_{2} \mathrm{HPO}_{4}$ (99.9\%), and $\mathrm{Sm}_{2} \mathrm{O}_{3}$ (99.999\%) were purchased from Aldrich. First, according to the stoichiometric ratios, these starting materials were mixed and thoroughly ground in an agate mortar. The pre-sintered samples were then evenly transferred to a tube furnace at $800{ }^{\circ} \mathrm{C}$ for $1 \mathrm{~h}$ of decomposition of the calcium carbonate and strontium carbonate in air. Finally, the as-prepared powders were calcined at $1250^{\circ} \mathrm{C}$ for $5 \mathrm{~h}$ in air atmosphere, and the furnace was cooled down to room temperature before their removal.

\subsection{Characterization}

A series of the obtained $\mathrm{CaSr}_{2-2 x}\left(\mathrm{PO}_{4}\right)_{2}: x \mathrm{Sm}^{3+}, x \mathrm{Li}^{+}$phosphors were measured by XRD analysis (XD-3, PGENERAL, China) in the $2 \theta$ range of $10^{\circ}$ to $70^{\circ}$, with $\mathrm{Cu} \mathrm{K} \alpha$ radiation $(\lambda=0.15406$ $\mathrm{nm})$ operating at $40 \mathrm{kV}$ and $40 \mathrm{~mA}$. The step scanning rate $(2 \theta$ values ranging from $5^{\circ}$ to $120^{\circ}$ ) used for Rietveld analysis was $1 \mathrm{~s}$ per step with a step size of $0.02^{\circ}$. The PL and PLE spectra of the phosphors were measured on a F-4600 spectrofluorometer (HITACHI, Japan) with a photomultiplier tube operating at $500 \mathrm{~V}$, and a $150 \mathrm{~W}$ Xe lamp used as an excitation source. A $400 \mathrm{~nm}$ cut-off filter was used to eliminate the second-order emission. The temperature-dependent PL spectra were also measured on the same spectrofluorometer with a home-made heating controller. The $\mathrm{CaSr}_{2}\left(\mathrm{PO}_{4}\right)_{2}$ were observed by SEM using a Hitachis-520 instrument. The X-ray photoelectron spectroscopy (XPS, ESCALab250, Thermo Scientific, America) with monochromatic $150 \mathrm{~W} \mathrm{Al} \mathrm{K} \alpha$ radiation was used to detect $\mathrm{Sm}^{3+}$. The room-temperature luminescence decay curves were recorded with a spectrofluorometer (Horiba, JobinYvon TBXPS), using a tunable pulse laser radiation as the excitation source.

\section{Results and discussion}

\subsection{Crystal structure}

The valence charge is imbalanced when $\mathrm{M}^{n+}$ ions were substituted by $\mathbf{M}^{(n+1)}$. This is undesirable for the phosphor materials and decreases the luminescence intensity. To avoid the charge unbalance and the formation of vacancy in the sample, the $\mathrm{Li}^{+}$ions were employed as charge compensators and added along with the $\mathrm{Sm}^{3+}$ ions. The mechanism of charge compensation is that two $\mathrm{Sr}^{2+}$ ions are replaced by one $\mathrm{Sm}^{3+}$ ion and one $\mathrm{Li}^{+}$ion. Therefore, the crystallinity of
$\mathrm{CaSr}_{2}\left(\mathrm{PO}_{4}\right)_{2}: \mathrm{Sm}^{3+}, \mathrm{Li}^{+}$improves because the doping with $\mathrm{Li}^{+}$ lowers the crystallization temperature. The XRD patterns of the synthesized $\mathrm{CaSr}_{2-2 x}\left(\mathrm{PO}_{4}\right)_{2}: x \mathrm{Sm}^{3+}, x \mathrm{Li}^{+}(x=0.01,0.06,0.09$, $0.12,0.15$, and 0.18 ) are shown in Fig. 1. The XRD patterns of the synthesized $\mathrm{CaSr}_{2-1.5 x}\left(\mathrm{PO}_{4}\right)_{2}: x \mathrm{Sm}^{3+},(x=0.01,0.03,0.05,0.07$, 0.09, 0.12, 0.15 and 0.18) and $\mathrm{CaSr}_{2}\left(\mathrm{PO}_{4}\right)_{2}$ are shown in Fig. 2. The introduction of $\mathrm{Li}^{+}$did not have any significant influence on the structure of the as-prepared samples. All XRD patterns can be well fitted with the standard patterns of the $\mathrm{Ca}_{3}\left(\mathrm{PO}_{4}\right)_{2}$ (JCPDS no. 09-0169) belonging to the trigonal crystal system, with a space group of $R 3 c$ (161). This suggests that all samples are crystallized in the single phase. All diffraction peaks shifted to the smaller $2 \theta$ angle side (bigger $d$-spacing, i.e., interplanar distances), which can be ascribed to the substitution of $\mathrm{Ca}^{2+}$ by bigger $\mathrm{Sr}^{2+}$. The $\mathrm{Sm}^{3+}$ and $\mathrm{Li}^{+}$ions have been successfully

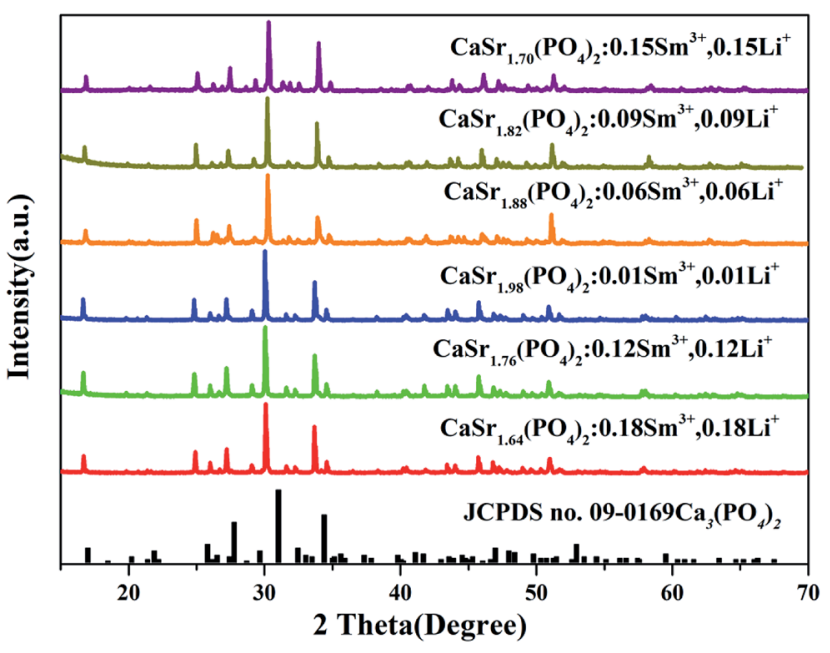

Fig. 1 The XRD patterns of $\mathrm{CaSr}_{2-2 x}\left(\mathrm{PO}_{4}\right)_{2}: \mathrm{XSm}^{3+}{ }_{,}, x \mathrm{Li}^{+}$phosphors $(x=$ $0.01,0.03,0.06,0.09,0.12,0.15,0.18,0.24,0.27$ and 0.3$)$ and the standard pattern of $\mathrm{Ca}_{3}\left(\mathrm{PO}_{4}\right)_{2}$ (JCPDS no. 09-0169) is shown as a reference.

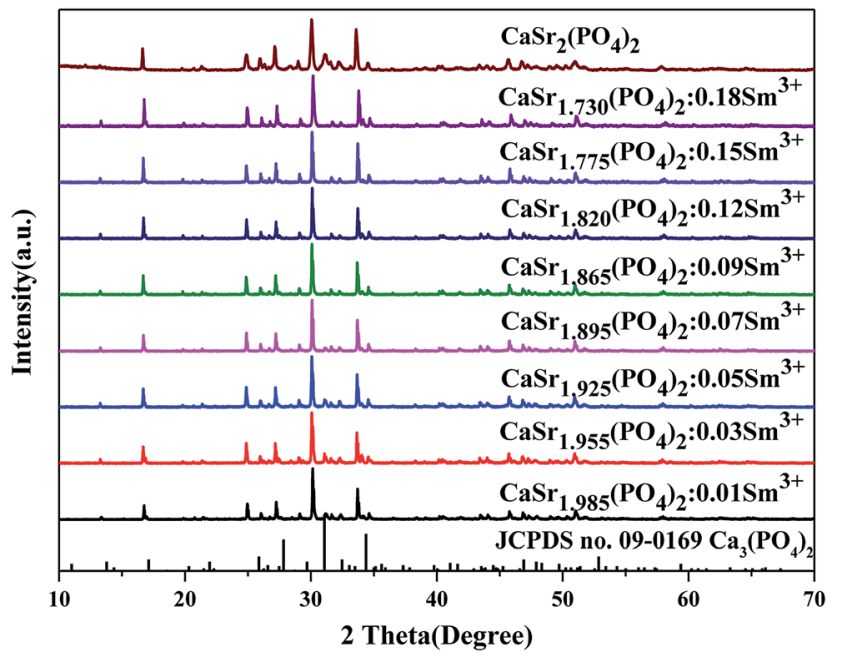

Fig. 2 The XRD patterns of $\mathrm{CaSr}_{2-2 x}\left(\mathrm{PO}_{4}\right)_{2}: x \mathrm{Sm}^{3+}$ phosphors $(x=0$, $0.01,0.03,0.05,0.07,0.09,0.12,0.15$ and 0.18 ) and the standard pattern of $\mathrm{Ca}_{3}\left(\mathrm{PO}_{4}\right)_{2}$ (JCPDS no. 09-0169) is shown as a reference. 
embedded into the crystal lattice-the $\mathrm{Sm}^{3+}$ and $\mathrm{Li}^{+}$dopant ions have no obvious influence on the structure of the host $\mathrm{CaSr}_{2}$ $\left(\mathrm{PO}_{4}\right)_{2}$ at various doping amounts. In order to further detect the phase purity of the phosphors, the $\mathrm{CaSr}_{1.82} \mathrm{Sm}_{0.09} \mathrm{Li}_{0.09}\left(\mathrm{PO}_{4}\right)_{2}$ was selected for refinements. Fig. S1 $\uparrow$ shows the Rietveld refinement of $\mathrm{CaSr}_{1.82} \mathrm{Sm}_{0.09} \mathrm{Li}_{0.09}\left(\mathrm{PO}_{4}\right)_{2}$ by TOPAS program. Solid red lines are calculated intensities, and blue circles are the observed intensities. Short orange vertical lines show the position of Bragg reflections of the calculated pattern. Green solid lines below the profiles stand for the difference between the observed and the calculated intensities. Refinement was stable and gives low $R$-factors (Table $\mathrm{S} 1$ and Fig. $\mathrm{S} 1 \dagger$ ). All the experimental peaks were well fitted by the refinement, indicating that all those peaks are Bragg reflections from the whitlockite structure. The lattice parameters of the phosphor are determined to be $a=b=10.5918(11) \AA, c=38.835(4) \AA$ and $V=$ 3773.06(55) $\AA^{3}$, respectively. The lattice parameters of the phosphor were a little different from $\mathrm{Ca}_{3}\left(\mathrm{PO}_{4}\right)_{2}$, which was caused by the isomorphic substitution. The refined atomic positions and isotropic temperature factors for all atoms are also shown in Table $\mathrm{S} 2 . \dagger$

Fig. 3 shows the crystal structure of $\mathrm{CaSr}_{2}\left(\mathrm{PO}_{4}\right)_{2}$ and different coordination environment for $\mathrm{Ca} / \mathrm{Sr}$ atoms. The crystal structure of the $\mathrm{CaSr}_{2}\left(\mathrm{PO}_{4}\right)_{2}$ is a result of the lattice deformation of $\mathrm{Ca}_{3}\left(\mathrm{PO}_{4}\right)_{2}$, via partial substitution of $\mathrm{Ca}^{2+}$ with $\mathrm{Sr}^{2+}$. In the crystal structure of the $\mathrm{CaSr}_{2}\left(\mathrm{PO}_{4}\right)_{2}$, the $\mathrm{Ca}^{2+} / \mathrm{Sr}^{2+}$ ions are distributed between five crystallographic sites-all of these are occupied by both $\mathrm{Ca}^{2+}$ and $\mathrm{Sr}^{2+}$ ions in different ways. The Sr1/ $\mathrm{Ca} 1, \mathrm{Sr} 2 / \mathrm{Ca} 2, \mathrm{Sr} 3 / \mathrm{Ca} 3, \mathrm{Sr} 4 / \mathrm{Ca} 4$ and $\mathrm{Sr} 5 / \mathrm{Ca} 5$ positions are coordinated with six, six, seven, three and six oxygen atoms, respectively. ${ }^{14}$ Of note, the $\mathrm{Ca} 4$ is threefold coordinated, suggesting weak bonding and the formation of crystal defects.

To investigate the composition and morphology of the material, the $\mathrm{CaSr}_{1.82}\left(\mathrm{PO}_{4}\right)_{2}: 0.09 \mathrm{Sm}^{3+}, 0.09 \mathrm{Li}^{+}$phosphor was selected as a representative example for measurements. Fig. 4(a) displays the elemental analysis result of the sample measured

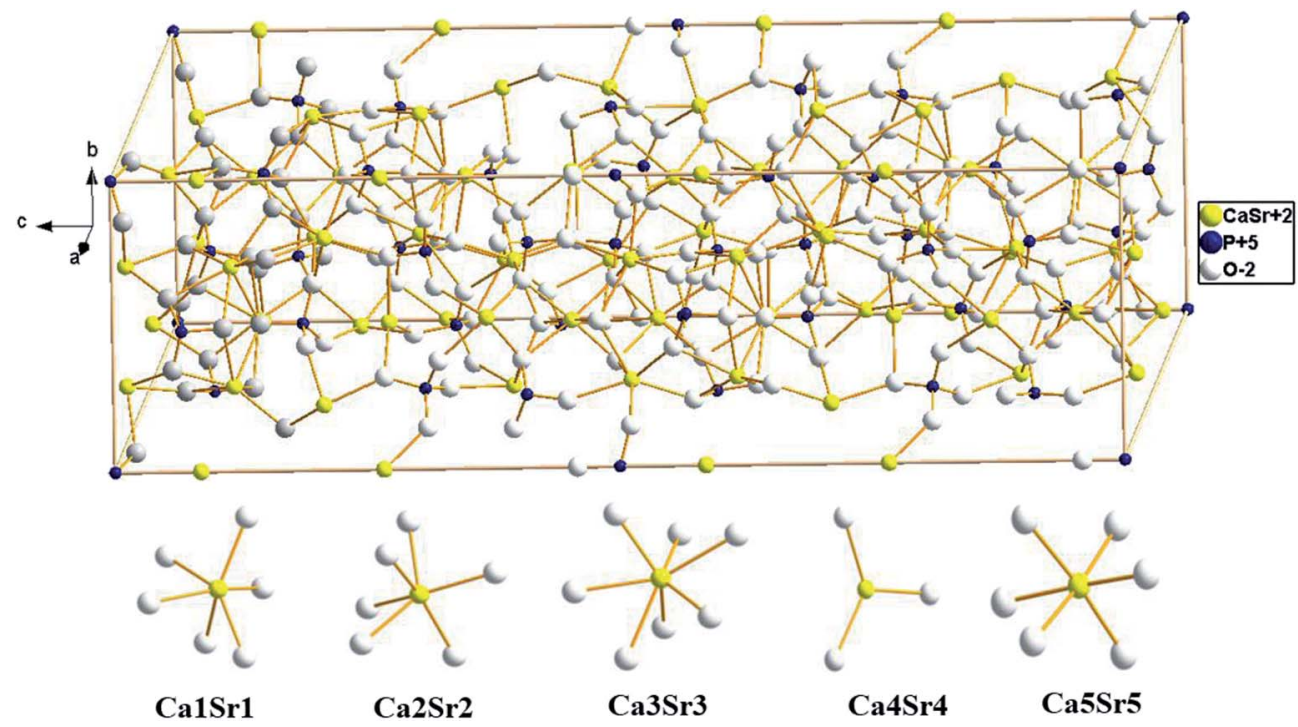

Fig. 3 Crystal structure of the host $\mathrm{CaSr}_{2}\left(\mathrm{PO}_{4}\right)_{2}$ compound, showing different coordination environment for $\mathrm{Ca} / \mathrm{Sr}$ atoms.

a)

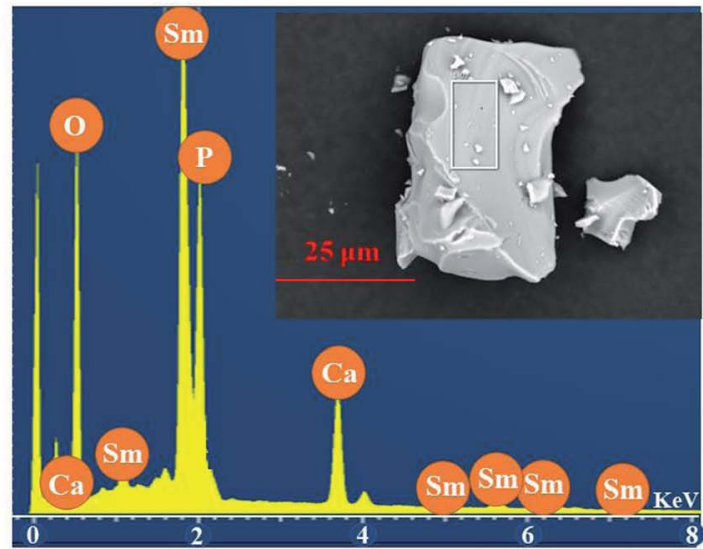

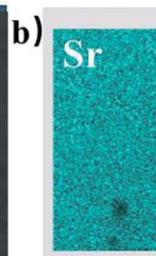
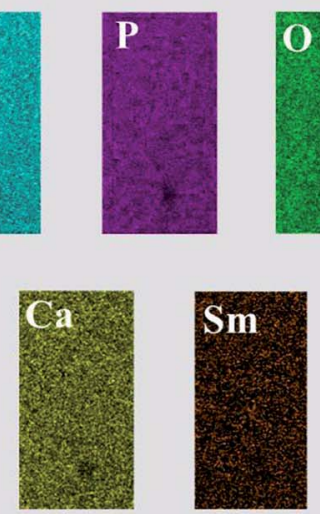

Fig. 4 (a) The elemental analysis result of the sample measured by the EDS method, within the red rectangle area and the inset showing the SEM image of the $\mathrm{CaSr}_{1.82}\left(\mathrm{PO}_{4}\right)_{2}: 0.09 \mathrm{Sm}^{3+}, 0.09 \mathrm{Li}^{+}$sample. (b) The elemental mapping of $\mathrm{CaSr}_{1.82}\left(\mathrm{PO}_{4}\right)_{2}: 0.09 \mathrm{Sm}^{3+}, 0.09 \mathrm{Li}^{+}$phosphors. 
by the EDS method, within the red rectangle area; the inset shows SEM images of the $\mathrm{CaSr}_{1.82}\left(\mathrm{PO}_{4}\right)_{2}: 0.09 \mathrm{Sm}^{3+}, 0.09 \mathrm{Li}^{+}$ sample with elemental mapping of $\mathrm{CaSr}_{1.82}\left(\mathrm{PO}_{4}\right)_{2}: 0.09$ $\mathrm{Sm}^{3+}, 0.09 \mathrm{Li}^{+}$phosphor provided in Fig. 4(b). The EDS results indicate that the synthesized phosphor is composed of $\mathrm{Ca}, \mathrm{Sr}, \mathrm{P}$, $\mathrm{O}$, and $\mathrm{Sm}$, which is consistent with the composition of $\mathrm{CaSr}_{1.82}\left(\mathrm{PO}_{4}\right)_{2}: 0.09 \mathrm{Sm}^{3+}, 0.09 \mathrm{Li}^{+}$material. The SEM image reveals that the as-prepared samples are well-crystallized. The sample consists of irregular crystal sizes ( $\approx 1000-2000 \mathrm{~nm})$.

The Sm 3d core level X-ray photoelectron spectra (XPS) of $\mathrm{CaSr}_{1.82}\left(\mathrm{PO}_{4}\right)_{2}: 0.09 \mathrm{Sm}^{3+}, 0.09 \mathrm{Li}^{+}$were measured to confirm the existence of $\mathrm{Sm}^{3+}$, as shown in Fig. 5. These data indicate the existence of trivalent oxidation states of Sm on the sample's surface. Only $\mathrm{Sm}^{3+}$ can be found; no peaks of $\mathrm{Sm}^{2+}$ can be seen. The XPS results are consistent with the EDS results.

\subsection{Photoluminescence properties}

Fig. 6 shows the PLE spectra of the $\mathrm{CaSr}_{2-2 x}\left(\mathrm{PO}_{4}\right)_{2}: x \mathrm{Sm}^{3+}, x \mathrm{Li}^{+}(x$ $=0.01-0.3$ ) phosphors monitored at $601 \mathrm{~nm}$ and room temperature. All PLE spectra have strong and narrow absorption bands ranging from 250 to $550 \mathrm{~nm}$ in the UV and visible range. These are ascribed to the intrinsic $4 \mathrm{f}^{5}-4 \mathrm{f}^{5}$ transitions of $\mathrm{Sm}^{3+}$ ions. ${ }^{15}$ The observed peaks around 305, 318, 333, 345, 375, 391, $403,416,440,466$ and $477 \mathrm{~nm}$, correspond to the transitions from the ground level ${ }^{6} \mathrm{H}_{5 / 2}$ to the excited levels ${ }^{4} \mathrm{P}_{5 / 2},{ }^{4} \mathrm{P}_{3 / 2},{ }^{4} \mathrm{G}_{7 / 2}$, ${ }^{4} \mathrm{D}_{7 / 2},{ }^{6} \mathrm{P}_{7 / 2},{ }^{2} \mathrm{~L}_{15 / 2},{ }^{4} \mathrm{~F}_{7 / 2},{ }^{6} \mathrm{P}_{5 / 2},{ }^{4} \mathrm{M}_{17 / 2},{ }^{4} \mathrm{H}_{13 / 2}$, and ${ }^{4} \mathrm{I}_{11 / 2}$ of $\mathrm{Sm}^{3+}$, respectively. ${ }^{16-18}$ The most intense band in the PLE spectra is located at $403 \mathrm{~nm}$, in the near-UV region.

Fig. 7 depicts the PL spectra of the $\mathrm{CaSr}_{2-2 x}\left(\mathrm{PO}_{4}\right)_{2}: x \mathrm{Sm}^{3+}, x \mathrm{Li}^{+}$ $(x=0.01-0.3)$ phosphors measured at room temperature excited at $403 \mathrm{~nm}\left({ }^{6} \mathrm{H}_{5 / 2} \rightarrow{ }^{4} \mathrm{~F}_{7 / 2}\right)$; the inset shows the dependence of the emission intensity at 707, 647, 601, and $565 \mathrm{~nm}$ on the $\mathrm{Sm}^{3+}$ doping concentration.

All PL spectra exhibit similar profiles with four emission peaks typical of $\mathrm{Sm}^{3+}$, associated with ${ }^{4} \mathrm{G}_{5 / 2} \rightarrow{ }^{6} \mathrm{H}_{J}(J=5 / 2,7 / 2,9 / 2,11 / 2)$ transitions in $\mathrm{Sm}^{3+}$ ions. ${ }^{\mathbf{1 9 , 2 0}}$ The inset in Fig. 7 shows the

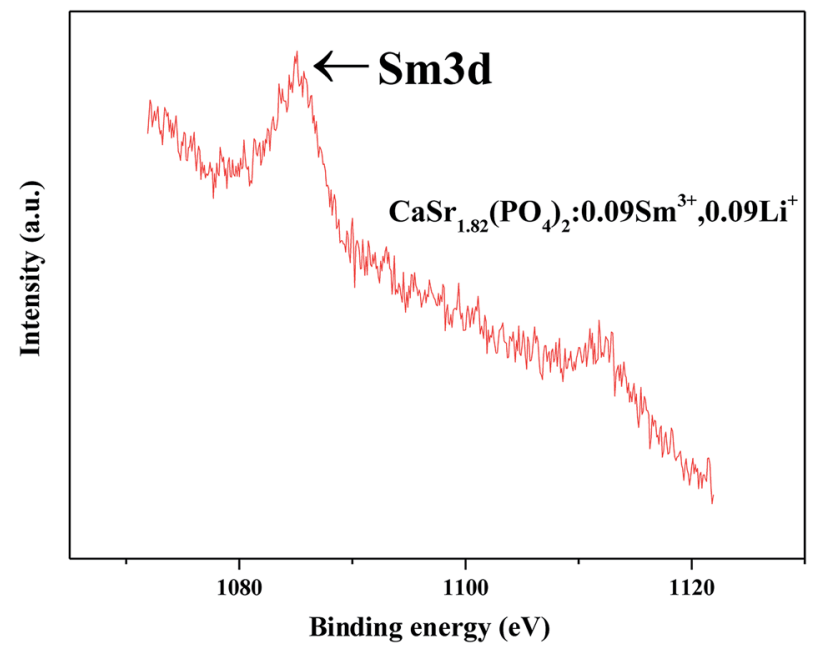

Fig. $5 \mathrm{Sm} \mathrm{3d}$ core level X-ray photoelectron spectra (XPS) of $\mathrm{CaSr}_{1.82}\left(\mathrm{PO}_{4}\right)_{2}: 0.09 \mathrm{Sm}^{3+}, 0.09 \mathrm{Li}^{+}$. dependence of emission intensity on the $\mathrm{Sm}^{3+}$ doping concentration at 565, 601, 647, and $707 \mathrm{~nm}$ corresponding to the electronic transitions of ${ }^{4} \mathrm{G}_{5 / 2} \rightarrow{ }^{6} \mathrm{H}_{5 / 2},{ }^{4} \mathrm{G}_{5 / 2} \rightarrow{ }^{6} \mathrm{H}_{7 / 2},{ }^{4} \mathrm{G}_{5 / 2} \rightarrow{ }^{6} \mathrm{H}_{9 / 2}$, and ${ }^{4} \mathrm{G}_{5 / 2} \rightarrow{ }^{6} \mathrm{H}_{11 / 2}$, respectively. ${ }^{15}$ In addition, the ${ }^{4} \mathrm{G}_{5 / 2} \rightarrow{ }^{6} \mathrm{H}_{7 / 2}$ transition (at $601 \mathrm{~nm}$ ) is the strongest one. There are no significant variations in the emission band positions or shape in any phosphor. The inset of Fig. 7 shows that the emission intensities at $565,601,647$, and $707 \mathrm{~nm}$ increase with the concentration of $\mathrm{Sm}^{3+}$ ions. They then reach a maximum when the concentration of $\mathrm{Sm}^{3+}$ is 0.09 . Finally, they decrease with further increases in $\mathrm{Sm}^{3+}$ content which corresponds to the concentration quenching effect. $^{21}$ The quantum efficiency of the $\mathrm{CaSr}_{1.82}\left(\mathrm{PO}_{4}\right)_{2}: 0.09$ $\mathrm{Sm}^{3+}, 0.09 \mathrm{Li}^{+}$phosphor is $9.23 \%$.

Fig. 8(a) shows the emission spectra of $\mathrm{CaSr}_{2}\left(\mathrm{PO}_{4}\right)_{2}: 0.03$ $\mathrm{Sm}^{3+}, x \mathrm{Li}^{+}(x=0.01,0.02$ and 0.03$)$ phosphors and the emission spectra of $\mathrm{CaSr}_{2}\left(\mathrm{PO}_{4}\right)_{2}: 0.03 \mathrm{Sm}^{3+}, x \mathrm{Na}^{+}(x=0.01)$ under $403 \mathrm{~nm}$ excitation. The emission spectra of $\mathrm{CaSr}_{2}\left(\mathrm{PO}_{4}\right)_{2}: 0.03 \mathrm{Sm}^{3+}, \mathrm{Li}^{+} /$ $\mathrm{Na}^{+}$samples include some peaks centered at 565, 601, 647 and 707 which are similar to those mentioned in Fig. 7. The inset shows the dependence of the emission intensity at $601 \mathrm{~nm}$ on the $\mathrm{Li}^{+} / \mathrm{Na}^{+}$doping concentration. This indicates that $\mathrm{Li}^{+}$ enhances the luminescent intensity of phosphors and is more effective than $\mathrm{Na}^{+}$. Fig. 8(b) illustrates the emission spectra of $\mathrm{CaSr}_{2-1.5 x}\left(\mathrm{PO}_{4}\right)_{2}: x \mathrm{Sm}^{3+},(x=0.03-0.18)$ phosphors, and the inset shows the dependence of the emission intensity at $601 \mathrm{~nm}$ on the $\mathrm{Sm}^{3+}$ doping concentration. We see that the luminescence trend of the phosphor at $601 \mathrm{~nm}$ is similar to that shown in Fig. 7. The luminescence increases with increasing concentration of $\mathrm{Li}^{+}$ions. The maximum luminescence intensity is achieved at $3 \% \mathrm{Li}^{+}$doping content. The phosphors need to produce ion defects to maintain the charge balance because the replacement of $\mathrm{Sr}^{2+}$ with $\mathrm{Sm}^{3+}$ is not equal. However, too many defects produce crystal lattice distortions that reduce the luminescence intensity. The excess positive charge from $\mathrm{Li}^{+}$ ions can be compensated by ion defects according to the following formula: $2 \mathrm{Sr}^{2+}=\mathrm{Sm}^{3+}+\mathrm{Li}^{+}$. This enhances luminescence intensity. There is also an effect on the change in asymmetry. It is reasonable to assume that the $\mathrm{Li}^{+}$doping changed the local environment of crystal field reducing the local environment symmetry, which in turn enhanced the emission intensity.

\subsection{Energy transfer mechanism}

It is well-known that the decrease in the photoluminescence intensity is mainly due to the concentration quenching of $\mathrm{Sm}^{3+}$ ions, which is usually caused by the cross-relaxation energy transfer between $\mathrm{Sm}^{3+}$ ions. ${ }^{22}$ The critical distance $R_{\mathrm{c}}$ for the energy transfer between $\mathrm{Sm}^{3+}$ ions can be estimated using the following equation proposed by Blasse: ${ }^{23}$

$$
R_{\mathrm{c}} \approx 2\left[\frac{3 V}{4 \pi x_{\mathrm{c}} N}\right]^{1 / 3},
$$

in which $V$ stands for the volume of the unit cell, $x_{\mathrm{c}}$ is the critical concentration of activator ion $\left(\mathrm{Sm}^{3+}\right)$ beyond concentration quenching, and $N$ represents the number of host cations in one unit cell. In our case, $N=10, V$ was estimated to be $626.5 \AA$, and $x_{\mathrm{c}}$ 


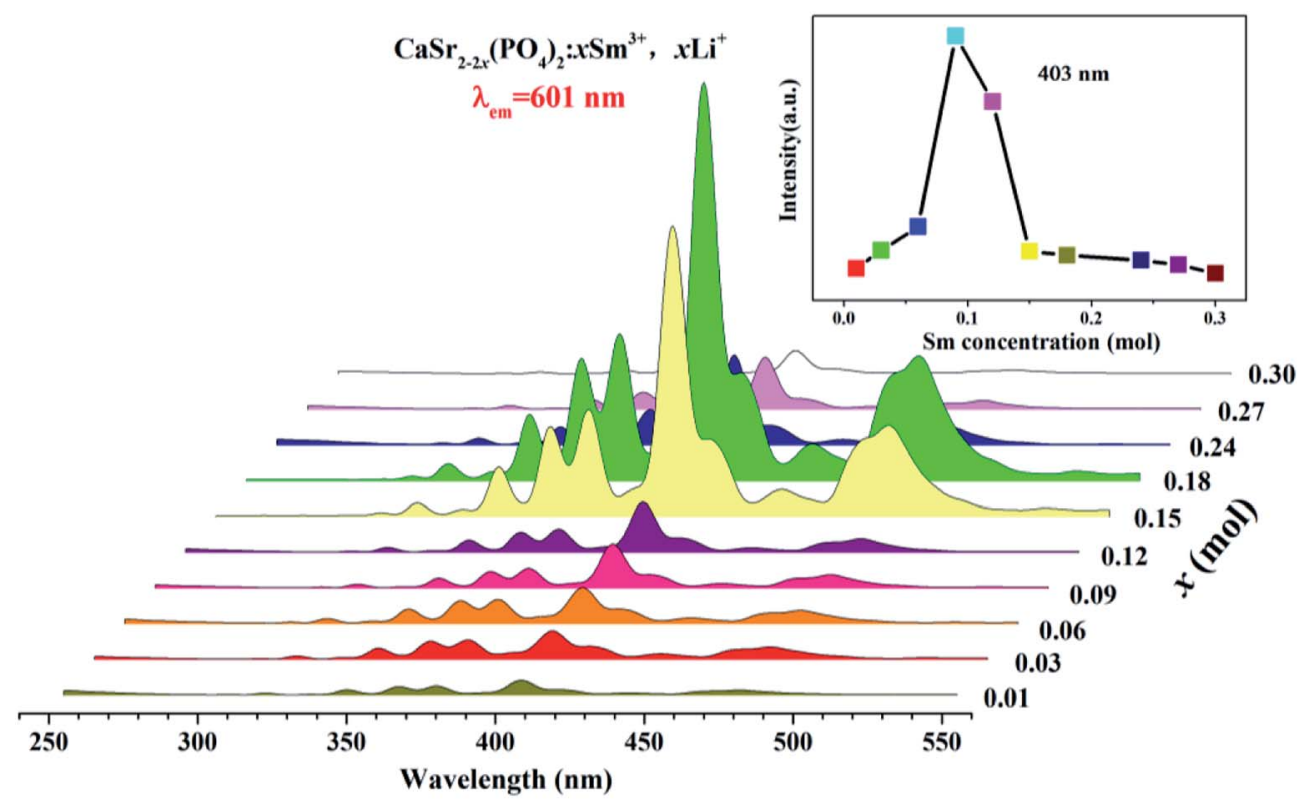

Fig. 6 The PLE spectra of the $\mathrm{CaSr}_{2-2 x}\left(\mathrm{PO}_{4}\right)_{2}: \mathrm{xSm}^{3+}{ }_{,} \mathrm{Lii}^{+}(x=0.01-0.3)$ phosphors, measured at room temperature and monitored at $601 \mathrm{~nm}$; the inset shows the dependence of the excitation intensity at $403 \mathrm{~nm}$ on the $5 \mathrm{~m}^{3+}$ doping concentration.

is 0.09 according to the above discussions. According to eqn (1), $R_{\mathrm{c}}$ was turned to $10.99 \AA\left(x_{\mathrm{c}}=0.09\right)$. It is well-known that exchange interactions play a vital role in the energy transfer mechanism when the critical distance between the sensitizer and the activator ions is less than $4 \AA$. With a much bigger $R_{\mathrm{c}}$ value, the energy transfer mechanism is considered to be an electric multipolar interaction. Based on Dexter's theory, if the energy transfer occurs by electric multipolar interactions, then the relationship between the luminescent intensity $(I)$ and the activator concentration $(x)$ can be expressed by the following equation: ${ }^{24}$

$$
\frac{1}{x}=K\left[1+\beta(x)^{\frac{\theta}{3}}\right]^{-1}
$$

Here $x$ is the activator concentration, and $\theta$ is a multipolar interaction constant equal to $3,6,8$ or 10 corresponding to the nearest-neighbor ions, i.e., dipole-dipole (d-d), dipole-

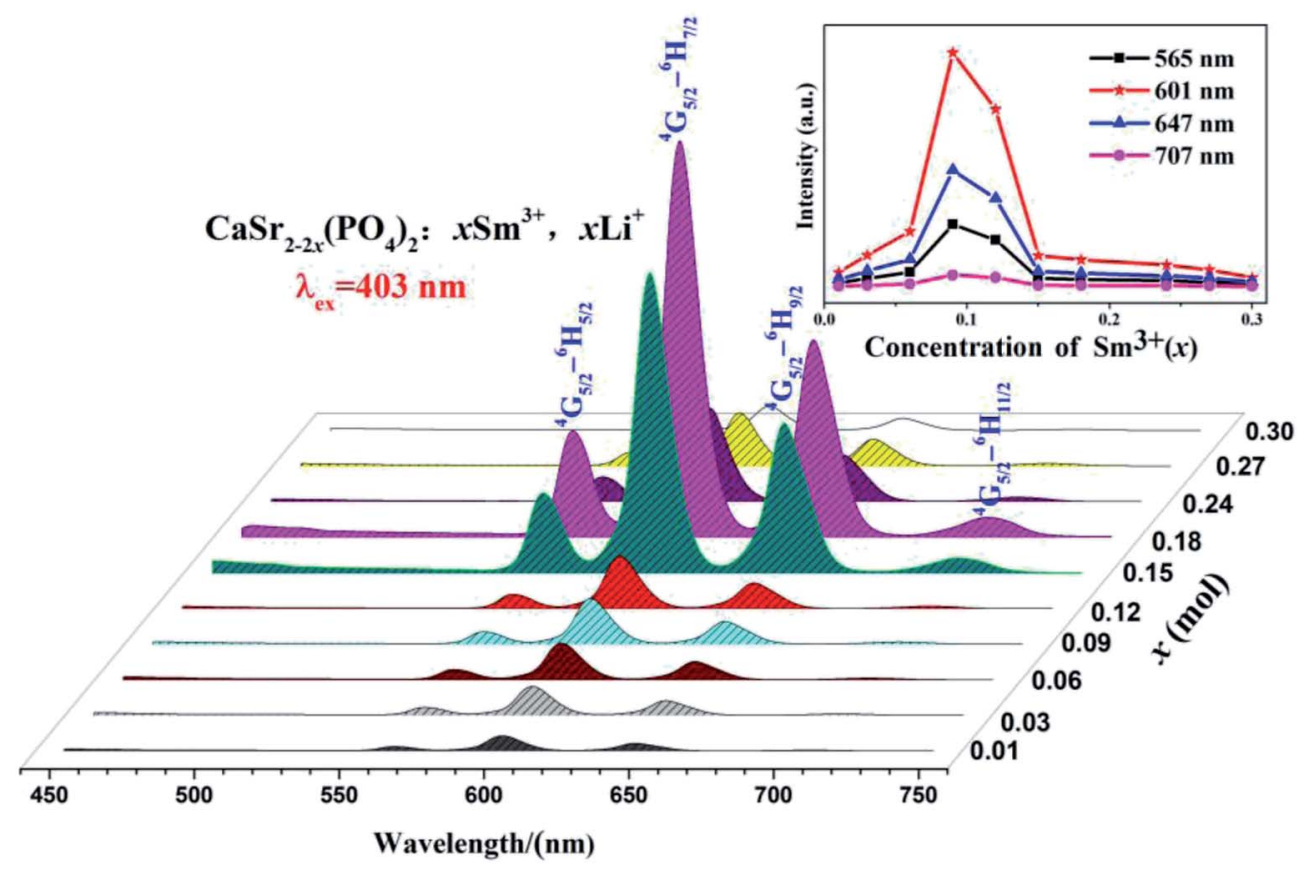

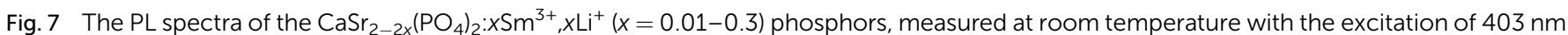
$\left({ }^{6} \mathrm{H}_{5 / 2} \rightarrow{ }^{4} \mathrm{~F}_{7 / 2}\right)$; the inset shows the dependence of the emission intensity at 707, 647, 601 and $565 \mathrm{~nm}$ on the Sm ${ }^{3+}$ doping concentration. 

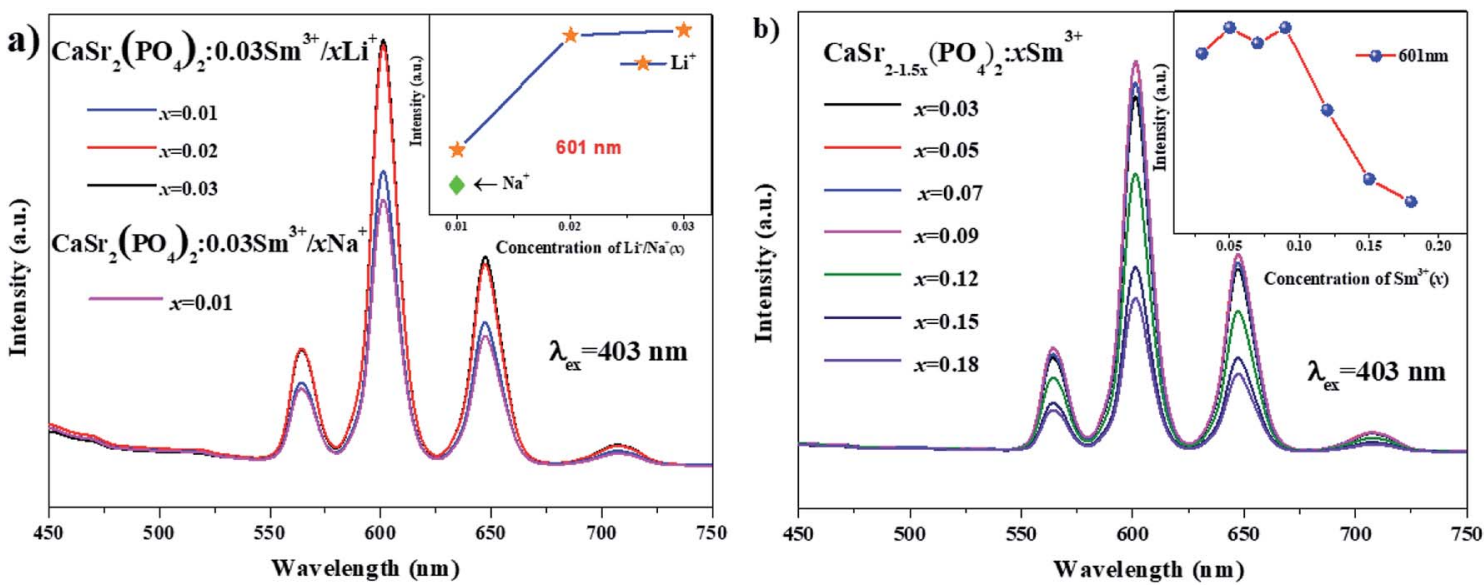

Fig. 8 (a) The emission spectra of $\mathrm{CaSr}_{2}\left(\mathrm{PO}_{4}\right)_{2}: 0.03 \mathrm{Sm}^{3+}, x \mathrm{Li}^{+}(x=0.01,0.02$ and 0.03$)$ phosphors and the emission spectra of CaSr 2 $\left(\mathrm{PO}_{4}\right)_{2}: 0.03 \mathrm{Sm}^{3+}, x \mathrm{Na}^{+}(x=0.01)$; the inset shows the dependence of the emission intensity at $601 \mathrm{~nm}$ on the $\mathrm{Li}^{+} / \mathrm{Na}^{+}$doping concentration. (b) The emission spectra of $\mathrm{CaSr}_{2-1.5 x}\left(\mathrm{PO}_{4}\right)_{2}: \mathrm{xSm}^{3+}(x=0.03-0.18)$ phosphors; the inset shows the dependence of the emission intensity at $601 \mathrm{~nm}$ on the $\mathrm{Sm}^{3+}$ doping concentration.

quadrupole $(\mathrm{d}-\mathrm{q})$, and quadrupole-quadrupole $(\mathrm{q}-\mathrm{q})$ interactions, respectively, ${ }^{25}$ Terms $K, \beta$ are constants for each interaction at the same excitation. ${ }^{26}$ Exceeding the quenching concentration, we chose the $\mathrm{CaSr}_{1.82}\left(\mathrm{PO}_{4}\right)_{2}: 0.09 \mathrm{Sm}^{3+}, 0.09 \mathrm{Li}^{+}$ samples for the constant emission intensity measurements at $601 \mathrm{~nm}$. The relation of $\log (I / x)$ vs. $\log (x)$ for the $\mathrm{CaSr}_{2-2 x}$ $\left(\mathrm{PO}_{4}\right)_{2}: x \mathrm{Sm}^{3+}, x \mathrm{Li}^{+}(x=0.12,0.15,0.18,0.24,0.27$ and 0.3$)$ of the peaks at 565, 601, 647 and $707 \mathrm{~nm}$ were plotted and depicted in Fig. 9. All $\theta$ values are close to 10 , which means that the quenching mechanism between $\mathrm{Sm}^{3+}$ ions in the $\mathrm{CaSr}_{2}\left(\mathrm{PO}_{4}\right)_{2}$ samples belongs to quadrupole-quadrupole $(\mathrm{q}-\mathrm{q})$ interactions.

\subsection{Temperature-dependent luminescent properties}

The thermal stability of the phosphor is a key issue for high-power w-LEDs because the luminescence intensity for most phosphors

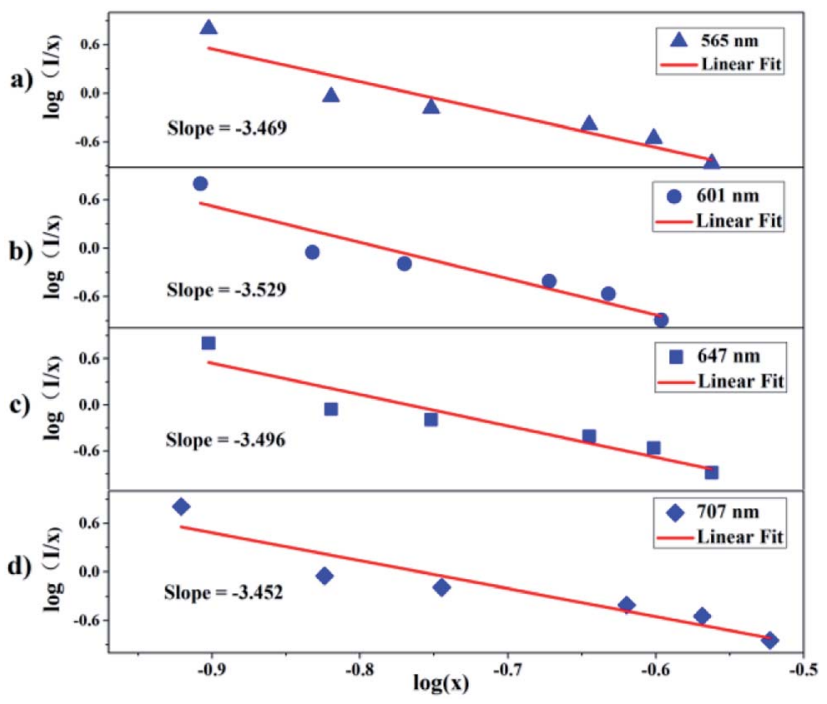

Fig. 9 Relationship between the $\log (/ / x)$ and $\log (x)$ of $\mathrm{Sm}^{3+}$ content in the $\mathrm{CaSr}_{2-2 x}\left(\mathrm{PO}_{4}\right)_{2}: x \mathrm{Sm}^{3+}, x \mathrm{Li}^{+}$phosphors beyond the quenching concentration, for the peaks at $565 \mathrm{~nm}$ (a), $601 \mathrm{~nm}$ (b), $647 \mathrm{~nm}$ (c) and $707 \mathrm{~nm}(\mathrm{~d})$. decreases if the operating temperature exceeds a certain value, i.e., temperature quenching. ${ }^{27}$ Fig. 10 shows the temperaturedependent emission spectra of the $\mathrm{CaSr}_{1.82}\left(\mathrm{PO}_{4}\right)_{2}: 0.09$ $\mathrm{Sm}^{3+}, 0.09 \mathrm{Li}^{+}$phosphor from 298 to $523 \mathrm{~K}$ with $403 \mathrm{~nm}$ excitation; the inset shows the relative emission intensities at 565, 601, 647, and $707 \mathrm{~nm}$ as a function of temperature. The shape of the emission bands remains nearly constant with increasing temperature (Fig. 10) suggesting that the phosphor has excellent color stability, which is crucial in LEDs or high temperature LEDs. However, with increasing temperature (from 300 to $350 \mathrm{~K}$ ), the emission peaks centered at 565, 601, 647, and $707 \mathrm{~nm}$ first slightly increase. These emission intensities decrease gradually when the temperature exceeds $350 \mathrm{~K}$. In contract to typical luminescence thermal quenching where the emission intensity decreases with increasing temperature, the emission characteristics of the obtained $\mathrm{Sm}^{3+}$-doped phosphors exhibit abnormal thermal quenching in the temperature range of $300-350 \mathrm{~K}\left(\lambda_{\mathrm{ex}}=403 \mathrm{~nm}\right)$. This abnormal thermal quenching phenomenon has also been found previously in the literature. ${ }^{28} \mathrm{We}$ assume that the energy transfer or temperature dependence of absorption coefficient might lead to this abnormal thermal quenching. When the temperature is higher than $350 \mathrm{~K}$, the decrease in PL intensities is due to the temperature-dependence of the electron-phonon interactions in both the ground and excited states of the luminescence center. The emission intensity of the $\mathrm{CaSr}_{1.82}\left(\mathrm{PO}_{4}\right)_{2}: 0.09 \mathrm{Sm}^{3+}, 0.09 \mathrm{Li}^{+}$phosphor at $384 \mathrm{~K}$ was $76.9 \%$ of baseline at $298 \mathrm{~K}$, revealing that the $\mathrm{CaSr}_{1.82}\left(\mathrm{PO}_{4}\right)_{2}: 0.09 \mathrm{Sm}^{3+}, 0.09 \mathrm{Li}^{+}$phosphors have good thermal stability. None of the samples had a temperature-induced shift in emission, which confirms the stable chromaticity coordinates of $\mathrm{CaSr}_{1.82}\left(\mathrm{PO}_{4}\right)_{2}: 0.09 \mathrm{Sm}^{3+}, 0.09 \mathrm{Li}^{+}$phosphors.

\subsection{Luminescence decay curves and chromaticity coordinates}

Fig. 11 shows the decay curves of $\mathrm{Sm}^{3+}$ emission for $\mathrm{CaSr}_{2-2 x^{-}}$ $\left(\mathrm{PO}_{4}\right)_{2}: x \mathrm{Sm}^{3+}, x \mathrm{Li}^{+}(x=0.01,0.06,0.12$ and 0.18$)$ samples excited at $403 \mathrm{~nm}$ and monitored at $601 \mathrm{~nm}$. All decay curves can be well fitted to a bi-exponential decay equation as follows: ${ }^{29,30}$ 


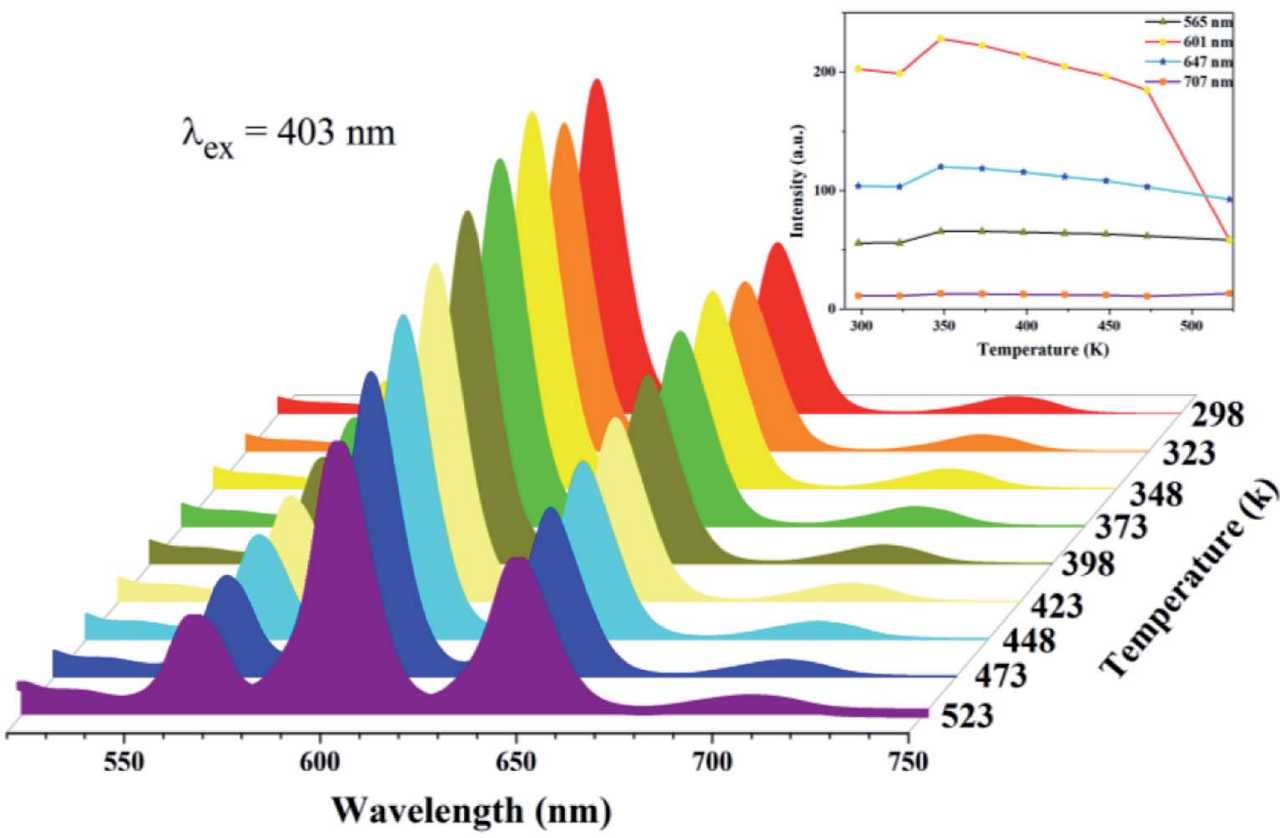

Fig. 10 The temperature-dependent emission spectra of the $\mathrm{CaSr}_{1.82}\left(\mathrm{PO}_{4}\right)_{2}: 0.09 \mathrm{Sm}^{3+}, 0.09 \mathrm{Li}^{+}$phosphor, in the temperature range of $298-$ $523 \mathrm{~K}$, under the excitation of $403 \mathrm{~nm}$; the inset shows the relative emission intensities at 565, 601, 647 and $707 \mathrm{~nm}$ as a function of temperature.

$$
I(t)=A_{1} \exp \left(-t / \tau_{1}\right)+A_{2} \exp \left(-t / \tau_{2}\right)
$$

where $I$ is the luminescence intensity at time $t, A_{1}$ and $A_{2}$ are amplitudes, and $\tau_{1}$ and $\tau_{2}$ are the luminescence lifetimes. The average emission lifetimes ( $\tau_{\text {average }}$ ) were calculated to be 1.14, $0.55,0.33$, and $0.17 \mathrm{~ms}$ for $\mathrm{CaSr}_{2-2 x}\left(\mathrm{PO}_{4}\right)_{2}: x \mathrm{Sm}^{3+}, x \mathrm{Li}^{+}$with $x=$ $0.06,0.12,0.18$, and 0.24 , respectively. Table 1 shows the calculated values of lifetimes and fitting parameters. Due to the decreasing distance between $\mathrm{Sm}^{3+}-\mathrm{Sm}^{3+}$ ions-and the resulting enhanced probability of energy transfer to luminescence killer sites-the emission lifetimes gradually shorten with increasing $\mathrm{Sm}^{3+}$ concentration. Thereby, the luminescence

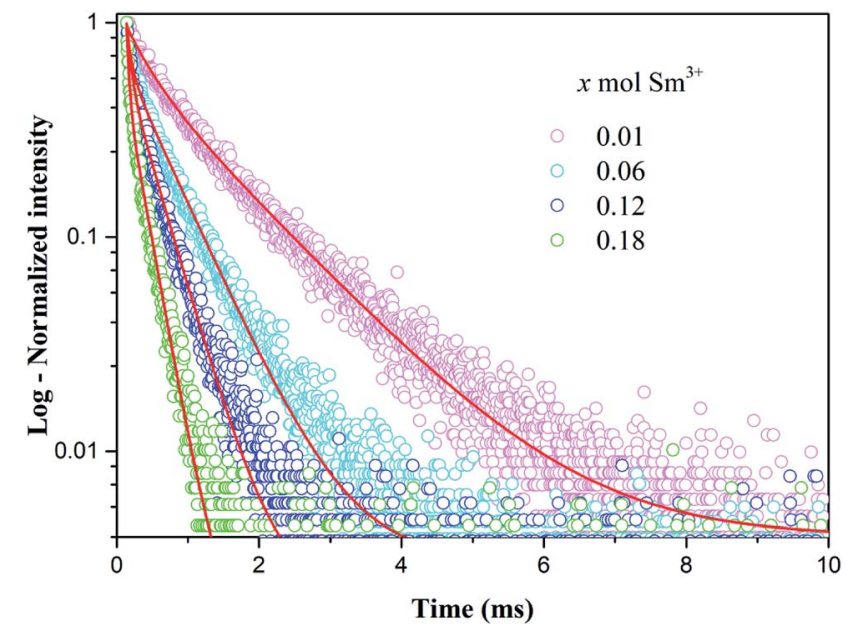

Fig. 11 Decay curves of $\mathrm{Sm}^{3+}$ emission in $\mathrm{CaSr}_{2-2 x}\left(\mathrm{PO}_{4}\right)_{2}: \mathrm{xSm}^{3+}, x \mathrm{Li}^{+}$ $(x=0.01,0.06,0.12$ and 0.18$)$ phosphors, measured at room temperature, under excitation at $403 \mathrm{~nm}$ and monitored at $601 \mathrm{~nm}$. lifetimes of $\mathrm{Sm}^{3+}$ ions are shortened due to the favorable nonradiative energy transfer processes when the $\mathrm{Sm}^{3+}$ concentration increases. Importantly, the contribution of the long-lived component $\left(\tau_{1} \approx 1.25-0.23 \mathrm{~ms}\right.$ ) decreases from about $65 \%$ to $22 \%$ with increasing $\mathrm{Sm}^{3+}$ concentration whereas the contribution of the short-lived component $\left(\tau_{2} \approx 0.33-0.03 \mathrm{~ms}\right)$ increases accordingly. This could be because of the non-equal occupation of the cation sites by the emitting activator $\mathrm{Sm}^{3+}$ that has a concentration-dependent preferential occupation in one of the sites as well.

The chromaticity diagram and Commission International de I'Eclairage (CIE) coordinates are very important because they indicate the exact emission color and color purity of the sample. ${ }^{31}$ The CIE chromaticity coordinates and the digital image of the $\mathrm{CaSr}_{1.82}\left(\mathrm{PO}_{4}\right)_{2}: 0.09 \mathrm{Sm}^{3+}, 0.09 \mathrm{Li}^{+}$phosphor excited at $403 \mathrm{~nm}$ are presented in Fig. 12. The CIE chromaticity coordinates $(x, y)$ of the phosphor were calculated to be $(0.5668$, $0.3904)$. They are located in the red region, which is consistent with the observed emission color of the phosphor under $403 \mathrm{~nm}$ excitation. Therefore, the $\mathrm{CaSr}_{2-2 x}\left(\mathrm{PO}_{4}\right)_{2}: x \mathrm{Sm}^{3+}, x \mathrm{Li}^{+}$material can be used as a red phosphor for w-LEDs in solid-state lighting applications.

Table 1 Determined luminescence lifetimes and fitting parameters for the $\mathrm{CaSr}_{2-2 x}\left(\mathrm{PO}_{4}\right)_{2}: x \mathrm{Sm}^{3+}{ }_{, x \mathrm{Li}^{+}}(x=0.01,0.06,0.12$ and 0.18$)$ samples

\begin{tabular}{lllllll}
\hline & & & & & $\tau_{\text {average }}$ \\
$x$ & $\tau_{1}(\mathrm{~ms})$ & $A_{1}(\%)$ & $\tau_{2}(\mathrm{~ms})$ & $A_{2}(\%)$ & $(\mathrm{ms})$ & $R^{2}$ \\
\hline 0.01 & 1.25 & 65.7 & 0.33 & 34.3 & 1.14 & 0.995 \\
0.06 & 0.59 & 60.7 & 0.07 & 39.3 & 0.55 & 0.996 \\
0.12 & 0.37 & 50.4 & 0.05 & 49.6 & 0.33 & 0.994 \\
0.18 & 0.23 & 22.2 & 0.03 & 77.8 & 0.17 & 0.993
\end{tabular}




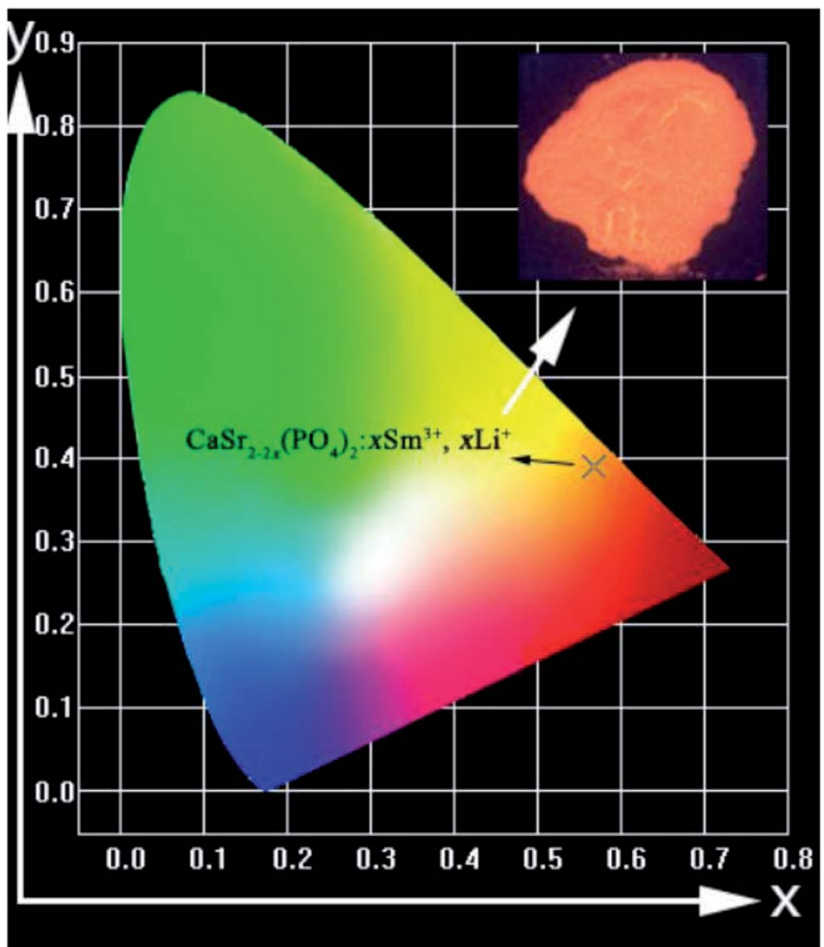

Fig. 12 Color coordinates for $\mathrm{CaSr}_{1.82}\left(\mathrm{PO}_{4}\right)_{2}: 0.09 \mathrm{Sm}^{3+}, 0.09 \mathrm{Li}^{+}$ material, in the $\mathrm{CIE}$ chromaticity diagram; the inset shows a digital photograph of the red-emitting phosphor excited at $403 \mathrm{~nm}$.

\section{Conclusions}

In summary, a series of $\mathrm{CaSr}_{2-2 x}\left(\mathrm{PO}_{4}\right)_{2}: x \mathrm{Sm}^{3+}, x \mathrm{Li}^{+}$phosphors were prepared for the first time by a conventional solid-state reaction. The phase structure, luminescence properties, thermal quenching, and emission decay curves were investigated. XRD patterns showed that the phosphor can be indexed to hexagonal apatite structure according to the results of crystal structure refinement. Under $403 \mathrm{~nm}$ excitation, the $\mathrm{CaSr}_{2-2 x}\left(\mathrm{PO}_{4}\right)_{2}: x \mathrm{Sm}^{3+}, x \mathrm{Li}^{+}$phosphors showed four emission bands centered at 565, 601, 647, and $707 \mathrm{~nm}$. The excitation spectra showed narrow excitation bands from 250 to $550 \mathrm{~nm}$ with a maximum at $403 \mathrm{~nm}$. This means that the phosphor can be effectively excited by UV chips for potential applications in $\mathrm{w}$ LEDs. The optimum dopant concentration of $\mathrm{Sm}^{3+}$ ions is 0.09 . Furthermore, the quenching mechanism between the $\mathrm{Sm}^{3+}$ ions was recognized as quadrupole-quadrupole $(\mathrm{q}-\mathrm{q})$ interactions. The dependence of the emission spectra on temperature indicated that the phosphor has a good thermal stability in both emission color and intensity. The CIE chromaticity coordinates of the selected $\mathrm{CaSr}_{2-2 x}\left(\mathrm{PO}_{4}\right)_{2}: x \mathrm{Sm}^{3+}, x \mathrm{Li}^{+}$sample were calculated to be $(0.5668,0.3904)$; they are located in the red-light region. These results indicated that $\mathrm{CaSr}_{2-2 x}\left(\mathrm{PO}_{4}\right)_{2}: x \mathrm{Sm}^{3+}, x \mathrm{Li}^{+}$phosphors have good potential for use as red-emitting luminophores for phosphor-converted w-LEDs.

\section{Conflicts of interest}

There are no conflicts to declare.

\section{Acknowledgements}

The present work is supported by the National Natural Science Foundation of China (Grant No. 41802040). Yuying Chen also thanks to the College Student Research Innovation Program of China University of Geosciences, Beijing.

\section{References}

1 Q. F. Guo, Q. D. Wang, L. W. Jiang, L. B. Liao, H. K. Liu and M. F. Mei, Phys. Chem. Chem. Phys., 2016, 118, 15545-15554. 2 X. X. Ma, L. B. Liao, Q. F. Guo, H. K. Liu, T. S. Zhou and L. F. Mei, RSC Adv., 2018, 8, 27332-27341.

3 Y. L. Zhu, Y. J. Liang, M. F. Zhang, M. H. Tong, G. G. Li and S. Wang, RSC Adv., 2015, 5, 98350-98360.

4 H. K. Liu, L. B. Liao, Q. F. Guo, D. Yang and L. F. Mei, J. Lumin., 2017, 181, 407-410.

5 M. F. Zhang, Y. J. Liang, R. Tang, D. Y. Yu, M. H. Tong, Q. Wang, Y. L. Zhu, X. Y. Wu and G. G. Li, RSC Adv., 2014, 4, 40626-40637.

6 G. G. Li, Y. Zhao, Y. Wei, Y. Tian, Z. W. Quan and J. Lin, Chem. Commun., 2016, 52, 3376-3379.

7 A. Shyichuk, R. T. Moura Jr, A. N. C. Neto, M. Runowski, M. Zarad, A. Szczeszak, S. Lis and O. L. Malta, J. Phys. Chem. C, 2016, 120, 28497-28508.

8 M. Runowski, J. j. Marciniak, T. Grzyb, D. Przybylska, A. Shyichuk, B. Barszcz, A. Katrusiak, S. Lis, A. Katrusiak and S. Lis, Nanoscale, 2017, 9, 16030-16037.

9 M. Runowski, S. Goderski, J. Paczesny, M. KsiężopolskaGocalska, A. Ekner-Grzyb, T. Grzyb, J. D. Rybka, M. Giersig and S. Lis, J. Phys. Chem. C, 2016, 120, 23788-23798.

10 W. J. Tang and Z. Zhang, J. Mater. Chem. C, 2015, 3, 53395346.

11 K. Li, D. L. Geng, M. M. Shang, Y. Zhang, H. Z. Lian and J. Lin, J. Phys. Chem. C, 2014, 118, 11026-11034.

12 H. Ji, Z. Huang, Z. Xia, M. S. Molokeev, V. V. Atuchin and S. Huang, Inorg. Chem., 2014, 53, 11119-11124.

13 J. Zhang, J. M. Jia and Z. H. Hua, Mater. Des., 2015, 87, 124129.

14 H. P. Ji, Z. H. Huang, Z. G. Xia, M. S. Molokeev, V. V. Atuchin, M. H. Fang and S. F. Huang, Inorg. Chem., 2014, 53, 51295135.

15 H. Ye, M. Y. He, T. S. Zhou, Q. F. Guo, J. L. Zhang, L. B. Liao, L. F. Mei, H. K. Liu and M. Runowski, J. Alloys Compd., 2018, 757, 79-86.

16 B. Ma, X. Q. Ma, T. H. Xu, K. Su and Q. X. Zhang, RSC Adv., 2018, 8, 14164-14169.

17 Q. F. Guo, C. L. Zhao, L. B. Liao, S. Lis, H. K. Liu, L. F. Mei and Z. Q. Jiang, J. Am. Ceram. Soc., 2017, 100, 1-11.

18 L. Li, X. H. Tang, Z. Q. Jiang, X. J. Zhou, S. Jiang, X. B. Luo, G. T. Xiang and K. N. Zhou, J. Alloys Compd., 2017, 701, 515-523.

19 T. S. Zhou, L. F. Mei, Y. Y. Zhang, L. B. Liao, H. K. Liu and Q. F. Guo, Opt. Laser Technol., 2019, 111, 191-195.

20 X. Y. Huang and H. Guo, Ceram. Int., 2018, 44, 10340-10344. 
21 R. Yu, H. Mi Noh, B. Kee Moon, B. Chun Choi, J. Hyun Jeong, H. Sueb Lee, K. Jang and S. Soo Yi, J. Lumin., 2014, 152, 133137.

22 Y. Zhang, B. Ding, L. Yin, J. Xin, R. Zhao, S. Zheng and X. Yan, Inorg. Chem., 2018, 57, 507-518.

23 G. Blasse, Philips Res. Rep., 1969, 24, 131-144.

24 D. L. Dexter and J. H. Schulman, J. Chem. Phys., 1954, 22, 1063-1070.

25 L. G. Van Uitert, J. Electrochem. Soc., 1967, 114, 1048-1053.

26 J. Xu, Z. H. Ju, X. P. Gao, Y. Q. An, X. L. Tang and W. S. Liu, Inorg. Chem., 2013, 52, 13875-13881.
27 T. Takeda, N. Hirosaki, S. Funahshi and R. Xie, Chem. Mater., 2015, 27, 5892-5898.

28 J. J. Chen, Y. Zhao, Z. Y. Mao, D. J. Wang and L. J. Bie, J. Lumin., 2017, 186, 72-76.

29 C. H. Huang and T. M. Chen, J. Phys. Chem. C, 2011, 115, 2349-2355.

30 R. Vijayakumar, H. Guo and X. Y. Huang, Dyes Pigm., 2018, 156, 8-16.

31 J. S. Kumar, K. Pavani, A. M. Babu, N. K. Giri, S. B. Rai and L. R. Moorthy, J. Lumin., 2010, 130, 1916-1923. 